
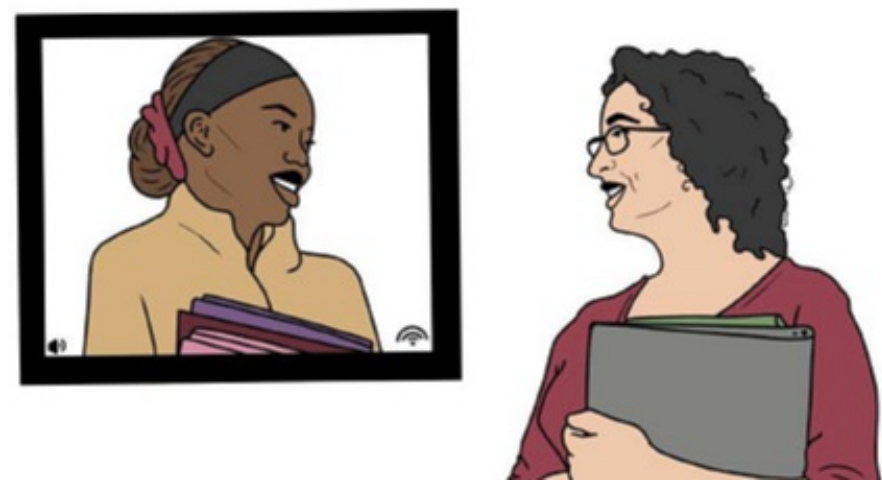

\title{
Technology-Enhanced Feedback in Higher Education: Source-Recipient Relationships in a New Dialogic Paradigm
}

\author{
Ameena Payne
}

Funding: The author(s) received no specific funding for this work.

Potential competing interests: The author(s) declared that no potential competing interests exist.

\section{Abstract}

Many universities across the globe have been required to abruptly move their education online in response to recent events. In Australia, those events include the 2019-2020 bushfire crisis and, of course, the current COVID-19 pandemic.

Technology has always been part of the human experience and has always existed as a disrupter. Prior to these challenging events, 'the twenty-first century was already bringing an increased emergence of new digital tools which have begun to profoundly change higher education institutions [HEIs]' ([1], 2020, p. 9).

Feedback is a cog in the pedagogical wheel. It is widely recognised that feedback is the driver of student learning ${ }^{[2]}$, 2007, p. 81). Students' application of course content is positively associated with feedback ( ${ }^{[3]} 2007$, p. 6). Yet, HEls are consistently criticised more by students about the quality of feedback than for almost any other aspect of their course (Boud \& Molloy, 2013, p. 698). Habits of assessments past are being replaced to make way for our digital world and diverse student cohorts $\left({ }^{[1]} 2020\right.$, p. v).

Digital is no longer a buzzword but resides at the heart of higher education. 'The danger is that in our rush to convert our practices from embodied to digital, that we will simply replicate what has been done' ([1], 2020, p. v). Pedagogic gaps and deficiencies are highlighted in digital learning environments $\left({ }^{[1]}, 2004\right.$, p. 173). Moreover, 'within the multitude demands of academia, teachers may not prioritise feedback, appreciate or understand it fully, or they may perceive that 
dialogic feedback is impractical' ([1], p. 99).

This conceptual article will examine the shift from feedback as one-way transmission to two-way Socratic, sustainable learning conversations. The article aims to explore the potential for technology to enhance relational dimensions of teaching practice. New paradigm approaches to feedback aim to utilise interrogative feedback $\left[{ }^{[1]}\right.$, p. 102) and Socratic discussion to facilitate a change in output (e.g. feedback uptake). The aim of feedback is to advise, encourage and improve output. The key is to empower institutions and therefore academics to reap the transformative benefits of digital innovation and encourage Socratic, sustainable and dialogic feedback through re-examining the relational dimensions of tutor/teacher relationships.

\section{Definitions}

Technology-enhanced feedback

Defined by Ameena Payne

Dialogic feedback

Defined by David Carless

\section{Introduction}

Technology has always been part of the human experience and has always existed as a disrupter. Prior to the current COVID-19 pandemic, the twenty-first century was already bringing an increased emergence of new digital tools which have begun to profoundly change higher education ([1] 2020, 9). Habits of assessments past are being replaced in order to make way for our digital world and diverse student cohorts $\left({ }^{[1]}, \mathrm{v}\right)$. Digital is no longer a buzzword but resides at the heart of higher education. 'The danger is that in our rush to convert our practices from embodied to digital, that we will simply replicate what has been done' (Bearman, Dawson, et al. 2020, v). Pedagogic gaps and deficiencies are highlighted in digital learning environments $\left({ }^{[4]}, 173\right)$. This conceptual article will examine the shift from feedback as one-way transmission to two-way Socratic, sustainable learning conversations and the move towards affiliation-dominated relationships. Further, the article aims to explore the potential for technology to reduce power differentials whilst simultaneously enhancing relational dimensions.

\section{Definition of Terms}

Dialogic feedback: Interactive exchanges between tutors and students which serve to share interpretations, clarify meaning and scaffold learning.

\section{A discoursal renaissance}

Feedback is a cog in the pedagogical wheel. In higher education institutions (HEIs), students are feedback seekers (recipients of feedback), whilst teachers/tutors are the targets of feedback seeking - or, in the context of this article, the 
source (or sender) of feedback; historically, this has implied a subordinate/dominate relationship between student and teacher. It is widely recognised that feedback is the driver of student learning (Hattie \& Timperley, 2007, p. 81). Students' application of course content is positively associated with feedback (Ice, Curtis, Phillips, \& Wells, 2007, p. 6). Yet, HEls are consistently criticised more by students about the quality of feedback than for almost any other aspect of their course (Boud \& Molloy, 2013, p. 698). It is widely recognised that students consistently report that feedback is provided sub-standardly in higher education (Hattie \& Timperley, 2007). According to Johnson and Johnson's (1994) Interpersonal Communication Model, 'various sources of noise can prevent clear messages from being transmitted; this noise may originate from the sender via lack of clarity or from the receiver via lack of attention' (Winstone, Nash, Rowntree, \& Parker, 2017, pp. 20262027). Moreover, 'within the multitude demands of academia, teachers may not prioritise feedback, appreciate or understand it fully, or they may perceive that dialogic feedback is impractical' (Winstone \& Carless, 2020, p. 99).

Dialogue is crucial to the feedback process (Nicol, 2010 as cited in Pitt \& Winstone, 2020, p. 79) and reduces power differentials between tutors and students. 'Dialogue is positioned within a view of feedback as a communicative act and a social process in which power, emotion, and discourse impact on how messages are constructed, interpreted, and acted upon' (Ajjawi \& Boud, 2017; 2018 as cited in Winstone \& Carless, 2020, p. 98). 'In support-dominated relationships, the principal method of feedback delivery is discussion - a two-way give-and-take conversation' (London, 1995, p. 166). A conversational tone initiated by the feedback provider may assist students in better understanding the feedback as there is a likelihood that less academic jargon is incorporated in verbal communication. Technology-enhanced feedback processes have been shown to solve many of the current criticisms of feedback.

In line with new paradigm approaches, audio-visual feedback can and should be implemented more effectively by encouraging and providing students the opportunity to respond (Winstone \& Carless, 2020, p. 68). Authentic assessment can be described as the degree of realism in varied workplaces and life situations which students may find themselves. As there has been a focus on authentic assessment, I feel that feedback as dialogue and the affordances of technology can mimic the kinds of conversations one may encounter in the workplace.

With an intention of minimising the power differential between teachers and students, interrogative feedback uses questioning to initiate dialogue and invite student response (Winstone \& Carless, 2020, p. 102). This experience tends to not be as encouraged in traditional, didactic education.

\section{Socratic, dialogic and sustainable feedback}

Winstone, Nash, Rowntree and Parker (2017) encourages readers and practitioners and conceive feedback as a communicative event. 'Beaumont, O'Doherty, and Shannon (2011) represent the feedback process as a 'dialogic cycle' (Winstone, Nash, Rowntree, \& Parker, 2017, p. 2027). Although students can seek feedback from many sources, including peers and other academic supports, I choose to focus on the tutor/teacher as a feedback source. 'As an act of communication, the feedback uptake process is also mediated and influenced by characteristics of the feedback context, 
message, provider and receiver' (Winstone et al. 2017 as cited in Wood, 2021, p. 2). Feedback is not just a medium for information, it is also a medium of power. Power, dominance and inclusion/exclusion can be illustrated through feedback.

Winstone and Carless (2020) express their belief that a dialogic approach to feedback is indeed possible with large class sizes (p. 103). They continue by emphasising the need for intentional design and the necessary shift away from teachertelling (p. 103). In what Boud and Molloy (2013) call ‘Feedback Mark 2', students are acknowledged as active coconstructors not rather than passive recipients. 'Feedback then becomes not a control mechanism designed by others to corral the learner, albeit in desirable ways, but a process used by learners to facilitate their own learning' (Boud \& Molloy, 2013, p. 703). According to constructivist theory, effective learning occurs 'by creating meaning from experience; what the learner knows is based on [their] own experience' (Merriam, 2018). Moreover, 'in adult learning theories, the learner takes responsibility [for their] learning process. The learners self-reflect, gather information, collaborate with others and are selfdirected' (Merriam, 2018).

Intellectual, introspective dialogue is the foundation of a Socratic approach to questioning. The early Greek philosopher/teacher, Socrates, believed that thoughtful questioning enabled the student to examine ideas rationally. 'Teachers need to communicate that the feedback is merely their point of view and that it could be open to dispute' (Jonsson, 2012, p. 69). Socratic questioning encourages student agency and self-regulated learning. This below table demonstrates how feedback may be adjusted so that interactions with students probe, encourage, empathise and engage.

Socratic questioning technique table (see Supplementary Data; Intel)

The Socratic probing technique is not used to intimidate, nor to patronise students, but instead for the very reason Socrates developed it: to scaffold critical-thinking skills in students and empower them to approach their learning with an academic lens.

'Research in online learning environments suggests that requests for explanation or clarification are aspects of new paradigm feedback practices and promote learning more effectively than corrective feedback (Guasch, Espasa, \& Martinez-Melo, 2019 as cited in Winstone \& Carless, 2020, p. 102). Askew and Lodge (2001, p. 1 as cited in Boud \& Molloy, 2013, p. 704) identified a characteristic of sustainable feedback as 'raising awareness of quality performance by involved students in dialogue'.

\section{Technology-enhanced feedback}

Technology has always been part of the human experience and has always existed as a disrupter. Prior to the current COVID-19 pandemic, the twenty-first century was already bringing an increased emergence of new digital tools which have begun to profoundly change higher education (Bearman, Boud, \& Ajjawi, 2020, p. 9). Digital is no longer a buzzword but resides at the heart of higher education. 
Given the recent rapid move to online higher education due to COVID-19, it is even more vital to re-evaluate teaching pedagogies and feedback methods and shift away from those that are not adequate in fostering community, communication and, ultimately, enhancing the digital learning environment. Written (text-based) feedback to students is the most widely used feedback method in online higher education (McCarthy, 2015). Pedagogic gaps and deficiencies are highlighted in digital learning environments (Dron, Seidel, \& Litten, 2004, p. 173).

Feedback is endemic to the pedagogic process. Current literature explores the affective implications, or feelings and attitudes, of the addition of technology-enhanced screen-casted feedback, particularly when compared with text-based feedback alone. 'Video feedback from peers or lecturers creates a social presence which is particularly important in overcoming feelings of isolation when studying remotely in online environments' (Carless, 2020, p. 5). Many studies have summarised the positive perceptions of text plus technology-enhanced feedback; when compared with text-based feedback alone, the findings demonstrated the addition of technology-enhanced feedback as preferred ${ }^{1,2}$, more effective for reception of assessment advice ${ }^{1}$, more effective at building rapport and a sense of community online ${ }^{3}$, more valuable $^{4}$ and able to further improve the overall usefulness and uptake of feedback ${ }^{5}$. Technology enables feedback to be more specific, detailed and individualized.

There are several key implications for a technology-enhance feedback practice. 'There is value in providing video feedback to help overcome some of the limitations of written-only comments' (Cavaleri et al., 2019) and to enhance students' engagement, learning and areas to improve. This is not to deny the value of text-based feedback; written and video feedback modes should be viewed as complementary (Cavaleri et al., 2019). 'Common themes in the written feedback could be highlighted in the video' (Cavaleri et al., 2019). Ideally, 'educators will prioritise using video for feedback on aspects of academic improvement that would benefit from a visual demonstration or verbal explanation so that they could exploit the affordances of screen-capture technology' (Cavaleri et al., 2019). Students may misconstrue textbased feedback. Technology-enhance feedback 'can help avoid misunderstandings which can result from interpreting written feedback' (Cavaleri et al., 2019). 'In this way the strengths, weaknesses and options for remedy could be delivered to the students in a way that might be more engaging than if the same information was written' (Kerr \& McLaughlin, 2008). Studies ${ }^{[4]}$ have shown that students rate the overall quality of feedback more highly if it were in video form. 'Furthermore, the amount of feedback communicated to the students with audio [-video] feedback has been reported to be significantly greater than the amount communicated with written feedback, without being more time-consuming' (Huang, 2000; Kirschner et al., 1991; Pearce and Ackley, 1995 as cited in Jonsson, 2012, p. 70).

Technology enables us to assess differently (Bearman, Dawson, Ajjawi, Tai, \& Boud, 2020, p. 6). Technology 'New paradigms of assessment are helping chart new directions' (Bearman, Dawson, Ajjawi, Tai, \& Boud, 2020, p. 8). However, 'the danger is that in our rush to convert our practices from embodied to digital, that we will simply replicate what has been done' (Bearman, Dawson, Ajjawi, Tai, \& Boud, 2020, p. v). Although higher education has been inundated with technology, it is a misstep to believe that 'education can be 'transformed through technology"' (Fullan, \& Langworthy, 
2013, p. 2 as cited in Winstone \& Carless, 2020, p. 60). 'In his 2014 book Digital Technology and the Contemporary University: Degrees of Digitisation, Selwyn calls for 'the very difficult conversations that need to take place about what digital higher education is, and what digital higher education should be.' From Selwyn's perspective, technology is not impartial: it serves a variety of different and often competing agendas. He notes that digital technologies tend to maintain the status quo; Selwyn suggests we need to reimagine higher education in this digital era' (Bearman, Boud, \& Ajjawi, 2020, p. 9). It is vital, then, to ensure that our use of digital tools is enabling dialogue, socio-affective support and cognitive scaffolding.

Winston \& Carless's discussions of a new paradigm approach (2020, p. 102) aims to utilise interrogative feedback and Socratic discussion to facilitate a change in output (e.g. feedback uptake). 'Technology is merely a tool like any other in a teacher's repertoire, and its effective use depends on its pedagogical use by teachers' (Winstone \& Carless, 2020, p. 2923). Hence, I am issuing a clarion call for intentionally designed digital feedback tools and processes that move beyond technology as yet another means of domineered 'telling' but to aim to empower, advise, encourage, probe, and provide opportunities for response. Technology-enhanced feedback provides tutors with the opportunity to engage in interactions that may increase social ties, create greater assurances and deepen connections.

\section{Source-recipient relationships}

Consistently in focus are the ideas about what makes a good teacher. It is important to continually consider these ideas as they are important in thinking about educational reform. Ideas about good teaching are rooted in education's design, technology and innovation. These ideas are contested, may vary between and within cultures and are open to change. Chinese Confucian custom, for example, defines the good teacher as a principled authority. As such, there has been one theme that has traditionally overshadowed the relationships between teaching staff and students in higher education. Habitually, teaching has been underpinned by an emphasis on respect, subordination and obedience of the student. Feedback techniques in control-dominated relationships tend to be unilateral.

Today's learners are entering the digital learning environment with a variety of pre-existing knowledge, aptitudes, opinions, and values which impact how they engage with and construe information. Texts have shifted to incorporate students as 'stakeholders', 'consumers, 'co-constructors' and 'active participants'; such terms are beginning to have a powerful rhetorical effect as the dynamic role of learners is acknowledged. "Feedback is no longer seen as a "gift" transmitted from expert to novice' (Wood, 2021, p. 3). Conceptions of relationships and of feedback have been required to shift from 'the mechanistic to the responsive' (Boud \& Molloy, 2013, p. 703).

Contemporary education, particularly higher education, has begun to shift away from teacher-dominated relationships to the role of teacher as facilitator, or 'affiliation (support) dominated relationships (London, 1995). "One ultimate goal of education is autonomy of the learner, but the teacher's role is to provide scaffolded learning opportunities" (Ewing, 2013). Literature has begun to emphasise the importance of rapport-building, humour and light-heartedness. 
The power of constructive and destructive interactions and varied relational dimensions inspire wide-ranging responses to feedback uptake. Literature in higher education often portrays a glum image (Winstone, Nash, Rowntree, \& Parker, 2017, p. 2027). What is it about feedback that gives it such influence over students' decisions to utilise it? The relationship that exists between the source and recipient may influence the uptake of feedback. I believe that students' perceived trustworthiness and care of the source is of importance. Jonsson (2013 as cited in Winstone et al. 2017, p 2028) takes a broader view and describe several reasons why students may not use feedback: '(1) it may not be useful; (2) it may not be sufficiently individualised; (3) it may be too authoritative'.

Table 1: Roles, Goals and Feedback Methods (London, 1995, p. 166)

Table 1

Roles, Goals, and Feedback Methods

\begin{tabular}{|c|c|c|}
\hline $\begin{array}{l}\text { Dominant Role in } \\
\text { Source-Recipient } \\
\text { Relationship }\end{array}$ & Source's Goal & $\begin{array}{l}\text { Feedback } \\
\text { Method }\end{array}$ \\
\hline \multicolumn{3}{|c|}{$\begin{array}{l}\text { Control-Dominated Relationships } \\
\text { Team Leader; } \\
\text { Supervisor/ }\end{array}$} \\
\hline Subordinate & $\begin{array}{l}\text { Teach/Evaluate } \\
\text { Direct/Control }\end{array}$ & $\begin{array}{l}\text { Inform } \\
\text { Instruct }\end{array}$ \\
\hline Student/Teacher & $\begin{array}{l}\text { Convey knowledge/ } \\
\text { Procedure } \\
\text { Instruct }\end{array}$ & $\begin{array}{l}\text { Demonstrate } \\
\text { Interpretation } \\
\text { Instruction } \\
\text { Description } \\
\text { Demonstration }\end{array}$ \\
\hline Mentor/Protege & Guide/Advise & Tutor/Counsel \\
\hline Critic/Public & Evaluate & $\begin{array}{l}\text { Description } \\
\text { Praise/Criticism }\end{array}$ \\
\hline \multicolumn{3}{|c|}{ Reward-Dominated Relationships } \\
\hline $\begin{array}{l}\text { Customer/Supplier } \\
\text { Competitors }\end{array}$ & $\begin{array}{l}\text { Meet Expectations } \\
\text { Beat the Competition }\end{array}$ & $\begin{array}{l}\text { Demand } \\
\text { Impress }\end{array}$ \\
\hline \multicolumn{3}{|c|}{ Affiliation-Dominated Relationships } \\
\hline $\begin{array}{l}\text { Friends } \\
\text { Co-Workers } \\
\text { Partners }\end{array}$ & $\begin{array}{l}\text { Suggest } \\
\text { Advise } \\
\text { Agree/Persuade } \\
\text { Build Trust } \\
\text { Win-Win }\end{array}$ & $\begin{array}{l}\text { Discussion } \\
\text { Discussion } \\
\text { Discussion } \\
\text { Consensus }\end{array}$ \\
\hline
\end{tabular}

Separate findings by Huang (2012) and Chuang et al. (2014) demonstrated that trust also dictates the likeliness of [students] seeking further feedback from the source to support improvement and future performance. Choi et al. (2014) expanded these findings in illustrating that the type of trust impacts the feedback seeking and uptake process. Specifically, Choi et al. (2014) demonstrated that both affect-based and cognitive-based trust is influential; affect- based trust (i.e., trust based on the source's perceived care toward the student) has a positive effect on feedback-seeking frequency and uptake. 
'Cognitive trust occurs when a person makes a conscious decision to trust based upon the best knowledge [they have]' (McAllister, 1995). Cognitive trust is often developed based on an individual's established dependability (McAllister, 1995). Therefore, each tutor-student interaction poses as an opportunity for cognitive-based trust to be either reinforced or reduced. Linked to the task-based side of work, cognitive trust in a student-tutor relationship may be build through the timely response to student queries. Affective trust is trust is often underpinned by security and based on emotions. It is within interactions that individuals cultivate affective-based trust.

Xu and Carless's (2017) case study highlight the approach taken by one participant to 'reduce the power distance between herself and the students' (p. 1086), and in turn, building a support-dominated relationship with her students. This was achieved by enabling approachability, reducing competition and facilitating a teamwork-based approach to learning (Xu \& Carless, 2017, p. 1087). Truly innovative teaching values diversity of perspectives which is underpinned by effective collaboration; collaboration is fueled by empathy. Collaborative brainstorming complemented by critical thinking builds and fosters a culture of mutual respect. Support-dominated relationships may positively influence affect, which in turn has the potential to stimulate feedback uptake and enhanced adjustment.

Table 4: Feedback Dimensions and Behaviors (London, 1995, p. 174) 
Table 4

Feedback Dimensions and Behaviors

\begin{tabular}{|c|c|c|}
\hline \multirow{2}{*}{$\begin{array}{l}\text { Feedback } \\
\text { Dimensions }\end{array}$} & \multicolumn{2}{|c|}{ Feedback Intention } \\
\hline & Constructive & Destructive \\
\hline \multirow{2}{*}{\multicolumn{3}{|c|}{$\begin{array}{l}\text { Control-Dominated } \\
\text { Relationships }\end{array}$}} \\
\hline & & \\
\hline Power & Empower & Domineer \\
\hline Negotiation Stance & Win-Win & Win-Lose \\
\hline Demeanor & Show Respect & Confront \\
\hline Tone & Be Patient & Be Curt \\
\hline Values & Enact the "Golden Rule" & "Do as I Say, Not as I Do" \\
\hline \multicolumn{3}{|l|}{ Reward-Dominated } \\
\hline \multicolumn{3}{|l|}{ Relationships } \\
\hline Behavior Continuity & Encourage & Discourage \\
\hline Confidence Building & Have a Can-Do-Attitude & $\begin{array}{l}\text { Belittle/Disparage/Ridicule/ } \\
\text { Demean } \\
\text { Use Name Calling }\end{array}$ \\
\hline Evaluation/Reward & $\begin{array}{l}\text { Positively Reinforce } \\
\text { Praise }\end{array}$ & $\begin{array}{l}\text { Negatively Reinforce; } \\
\text { Withhold Positive Rewards }\end{array}$ \\
\hline Favorable Attribution & Attribute Internally & Attribute Externally \\
\hline Negative Attribution & Attribute Externally & Attribute Internally \\
\hline Timing & "Do it Now" (immediately) & Delay/Procrastinate \\
\hline Focus & Focus on Task & Focus on Person \\
\hline \multicolumn{3}{|l|}{ Affiliation-Dominated } \\
\hline \multicolumn{3}{|l|}{ Relationships } \\
\hline Expression of Feelings & Be Controlled & Vent Emotions \\
\hline Communication & $\begin{array}{l}\text { Be Open } \\
\text { Encourage Two-Way } \\
\quad \text { Communication } \\
\text { Be Clear } \\
\text { Communicate Face-to-Face }\end{array}$ & $\begin{array}{l}\text { Be Close Lipped or } \\
\text { Engage in One-Way } \\
\text { Communication } \\
\text { Be Confusing } \\
\text { Be Indirect } \\
\text { Communicate "Behind-the- } \\
\text { Back" }\end{array}$ \\
\hline Revealing Self Bias & $\begin{array}{l}\text { Be Self-Disclosive } \\
\text { Provide Fair and Equal } \\
\text { Treatment } \\
\text { Give More Attention }\end{array}$ & $\begin{array}{l}\text { Be Self-Protective } \\
\text { Be Unfair } \\
\text { Discriminate } \\
\text { Withhold Attention }\end{array}$ \\
\hline \multicolumn{3}{|l|}{ Overall } \\
\hline Focus & Focus on Recipient & Focus on Self \\
\hline Behavior & $\begin{array}{l}\text { Be Tolerant and Patient } \\
\text { Be Supportive }\end{array}$ & $\begin{array}{l}\text { Be Intolerant and Impatient } \\
\text { Be Abusive }\end{array}$ \\
\hline Rationality & $\begin{array}{l}\text { Make Decisions That are } \\
\text { Clear and Logical } \\
\text { ("20-20" Rationality) }\end{array}$ & $\begin{array}{l}\text { Make Decisions That are } \\
\text { Confused or Misguided } \\
\text { (Corrective "lens" } \\
\text { Needed) }\end{array}$ \\
\hline
\end{tabular}

Although one type may dominate, elements of the various types of role relationships may be present (London, 1995, p.

166). For example, in an affiliation-dominated relationship, it is possible for one party to end up dominant and in a position of control (London, 1995, p. 166). Of course, even if insisting on taking an affiliate relationship, tutors are still marking the students' performance, which means that there are parts of the teacher's authority that cannot be overlooked (Jonsson, 2012, p. 69). London's (1995) model suggests one theme is likely to emerge and dictate the relationship and subsequently determine the feedback ambitions and processes.

Table 5: Outcome of the Feedback Cycle: Recipients Emotional Reactions (London, 1995, p. 176) 
Table 5

Outcome of the Feedback Cycle: Recipient's Emotional Reactions

\begin{tabular}{lll}
\hline & \multicolumn{2}{c}{ Feedback Reactions } \\
\cline { 2 - 3 } & Constructive & Destructive \\
\hline Control-Dominated & Independence Generating & Entrapped \\
Relationships & $\begin{array}{l}\text { Empowered } \\
\text { Self-Control }\end{array}$ & $\begin{array}{l}\text { Disabled } \\
\text { Cisenfranchised }\end{array}$ \\
& Clear Reward Contingencies & Managed \\
& Negotiation Latitude & Dependence \\
& & Anxiety \\
& & Threat \\
Reward-Dominated & Goal Clarity & \\
Relationships & Galatia Effect & Goal Ambiguity \\
& Increased Challenge & Loss \\
& Self-Confidence & Manipulated \\
& Gain & \\
& Pride & \\
Affiliation-Dominated & Trust & \\
Relationships & Confidence & Disharmony \& Dislike \\
& Fairness/Equity Treatment & Unfair treatment \\
& Friendship & Distrust \\
& Commonalities Emphasized & Differences Emphasized \\
& Lonesome \\
& Team & Outcast \\
& Expanding cycle of Growth & Constricting Cycle of \\
& and Development & Behavior Dysfunction \\
\hline & &
\end{tabular}

Although it has the potential to be constructive (London, 1995, p. 176), authoritative feedback is generally not perceived by students as fruitful (Jonsson, 2012); at best it is not useful; at worst, it has the immense potential to be perceived as destructive and domineering. Control-dominated relationships within higher education may be a barrier to student affect which subsequently reduces feedback seeking, uptake and adjustment. 'Dysthe et al. (2011) argue that teachers must insist on taking the part of a dialogue partner, rather than an authority in the classroom' (Jonsson, 2012, p. 69).

Implications

The experience offered by a new dialogic feedback paradigm strives for learners to feel empowered and respected.

'Students can only achieve a learning goal if they understand that goal, assume some ownership of it, and can assess progress' (Nicol \& Macfarlane-Dick, 2006, p. 202). I ask academics to consider the conditions that lend to ones' ability to refine their skillset and improve their understanding. Dialogue 'can signal a gap between a current level of performance and some desired level of performance or goal' (Shute, 2008, p. 154). Dialogue is an approach to intentional engagement with students. This involving approach enables students to take ownership over their learning process (Gosper \& Ifenthaler, 2014). Ideally this will 'facilitate a more strategic use of [learning materials and] feedback by the learner' (Crisp, 2010, p. 40). 
Challenging and minimising power differentials in higher education may be achieved by communicating in less formal, warm and conversational manners. Such communication may demonstrate care, gain trust and facilitate the sharing of information that is more easily understood by both parties. The request to minimise the power differential is a request for HEls to demonstrate that they are transforming, that they do not wish to dominate and demean, but rather respect and care for students as human beings. Something as simple as a two-way dialogue can reconfigure experiences and relationships between students and educators.

I believe technology-enhanced feedback should be presented as a pathway for encouraging learning conversations and self-regulation of students' approaches to their current and future learning. The use of technology-enhanced feedback can better prepare educators for meeting the (academic) diversity of learners.

The tradition of the imposing professor is quickly coming to an end. Those who rely on the Socratic Method today use participatory learning and discussions to explore concepts. The effort is a cooperative one in which the tutor and students work to understand an issue more completely. Dewey (1997) advocated for empowering learners by honouring their experiences and learning styles. In a democratic education, educators get to know their learners' situations and experiences. One must 'have that sympathetic understanding of individuals as individuals which gives [them] an idea of what is actually going on in the minds of those who are learning' (Dewey, 1997). In essence, Dewey is arguing for socialaffective support as well as cognitive scaffolding - for educators to meet learners where they are, wherever that may be.

\section{Conclusions}

Dialogue is a critical element of feedback, with the potential to improve uptake by the reduction of power differentials between students and teachers. Technology has the potential to assist in the shift of feedback processes from transmission to dialogic interaction. This may require academics to reflect on their own beliefs, behaviours and relationships within an education system that has been complicit in less-than-democratic feedback practices.

Times of great social unrest and uncertainty call for greater adaptability, empathy and innovation. It is a hope that this conceptual article can set the stage for understanding how educators can successfully use technology to enhance their feedback practice, leading to a reduction of student/tutor power differentials, improving the relational aspects of teaching and facilitation, and particularly, of improving student feedback uptake. Quality feedback and innovative assessment tools should serve not only as a metric for outcomes but should also facilitate and enrich the learning process itself. My aim for future research is to allow all educators to deeply consider their teaching practices more broadly, interconnectedly and innovatively. Uncertainty can give rise to long overdue reflection and transformation.

\section{Acknowledgements:}


I would like to acknowledge the Wurundjeri People of the Kulin Nation, as the traditional owners of the lands in which I live. I express my gratitude to the Wurundjeri People for their guardianship of this land, for which I have benefited. I pay my respects to all elders of the Kulin Nation, past, present and emerging.

Whilst I am engaging in contemporary knowledge, teaching and learning, I would also like to pay my respect to the knowledge embedded forever within Indigenous ways of knowing, and Aboriginal Custodianship of Country.

I would also like to thank Rola Ajjawi, Dr. Jessica Holloway, Phillip Dawson and David Carless for their ongoing support and kindness.

I acknowledge that parts of this manuscript are adapted from my Master of Education research proposal.

\section{Funding}

This literature was not funded. The author(s) received no financial support for the research, authorship, and/or publication of this article.

\section{Disclosure statement}

No potential conflict of interest was reported by the author.

\section{Biographical note:}

ORCiD: 0000-0001-9938-4144

Twitter:@ameenalpayne

Linkedln: www.linkedin.com/in/ameenapayne

Ameena is an educator within the disciplines of education and business in both vocational and higher education. She holds a Graduate Certificate in Learning and Teaching (Higher Education), Bachelor of Science in Business Administration, Diploma of Project Management and a Certificate IV in Training \& Assessment. She is currently pursuing her Master of Education (Research Intensive) at Deakin University where she is a Deakin International Scholarship recipient. Her interests are in learner analytics, assessment design and technology-enhanced feedback - not to mention equitable education and education reform.

\section{Works Cited}

Ashford, S. J., De Stobbeleir, K., \& Nujella, M. (2016). To Seek or Not to Seek: Is That the Only Question? Recent Developments in Feedback-Seeking Literature. Annual Review of Organizational Psychology and Organizational Behavior, 213-239. doi:10.1146/annurev-orgpsych-041015-062314 
Bearman, M., Boud, D., \& Ajjawi, R. (2020). Chapter 2: New Directions for Assessment in a Digital World. In M. Bearman, P. Dawson, R. Ajjawi, J. Tai, \& D. Boud, Re-imagining University Assessment in a Digital World (pp. 7-22). doi:https://doi.org/10.1007/978-3-030-41956-1

Bearman, M., Dawson, P., Ajjawi, R., Tai, J., \& Boud, D. (2020). Chapter 1: Introduction. In M. Bearman, P. Dawson, R. Ajjawi, J. Tai, \& D. Boud, Re-imagining University Assessment in a Digital World (pp. v-6). doi:https://doi.org/10.1007/9783-030-41956-1

Boud, D., \& Molloy, E. (2013). Rethinking models of feedback for learning: the challenge of design. Assessment \& Evaluation in Higher Education, 38(6), 698-712.

Carless, D. (2020). From teacher transmission of informatin to student feedback literacy: Activating the learner role in feedback processes. Active Learning in Higher Education, 1-11. doi:10.1177/1469787420945845

Carless, D., \& Boud, D. (2018). The development of student feedback literacy: enabling uptake of feedback. Assessment \& Evaluation in Higher Education, 43(8), 1315-1325. doi:https://doi.org/10.1080/02602938.2018.1463354

Choi, B., Moon, M., \& Nae EY. (2014). Cognition- and affect-based trust and feedback-seeking behavior: the roles of value, cost and goal orientations. J. Psychol.: Interdiscip. Appl., 148(5), 603-620.

Chuang, A., Lee, C., \& Shen, C. (2014). A multilevel perspective on the relationship between interpersonal justice. Can. J. Adm. Sci. Rev, 31, 59-74.

Connell, R. (2009). Good teachers on dangerous ground: towards a new view of teacher quality and professionalism. Critical Studies in Education, 99-112.

Crisp, G. T. (2010). Integrative assessment: reframing assessment practice for current and future learning. Assessment and Evaluation in Higher Education, 33-43.

Dewey, J. (1997). Experience and education. New York: Simon \& Schuster Inc.

Dron, J., Seidel, C., \& Litten, G. (2004). Transactional distance in a blended learning environment. ALT-J: Research in Learning Technology, 163-174.

Ewing, R. (2013). Chapter 2: Conflicting Ideologies: Objectives or Outcomes? In Curriculum and Assessment. Oxford University Press.

Gosper, M., \& Ifenthaler, D. (2014). Curriculum Design for the 21st Century. Springer Science, 1-14. 
Gutek, G. L. (1997). Philosophical and Ideological Perspectives on Education. (V. C. Lanigan, Ed.) Needham Heights, MA: Pearson.

Hattie, J., \& Timperley, J. (2007). The Power of Feedback. Review of Educational Research, 77(1), 81-112. Retrieved from https://doi.org/10.3102/003465430298487

Huang, J. (2012). Be proactive as empowered? The role of trust in one's supervisor in psychological empowerment, feedback seeking, and job performance. J. Appl. Soc. Psychol., 42(1), 103-127.

Ice, P., Curtis, R., Phillips, P., \& Wells, J. (2007). Using asynchronous audio feedback to enhance teaching presence and students' sense of community. Journal of Asynchronous Learning Networks, 3-25.

Jonsson, A. (2012). Facilitating productive use of feedback in higher education. Active Learning in Higher Education, 14(1), 63-76. doi:10.1177/1469787412467125

London, M. (1995). Giving feedback: Source-centered antecedents and consequences of constructive and destructive feedback (Vol. 5). Stony Brook, NY: JAI Press Inc.

McAllister, D. J. (1995). Affect and Cognitive-based Trust as Foundations for Interpersonal Cooperation in Organizations. Academy of Management Journal, 38(1), 24-59.

Merriam, S. B. (2018). Adult learning theory: Evolution and future directions. In I. Knud, Contemporary Theories of Learning: Learning Theorists ... In Their Own Words (pp. 83-96). London: Routledge.

Nicol, D., \& Macfarlane-Dick, D. (2006). Rethinking Formative Assessment in HE: A theoretical model and seven principles of good feedback practice. Studies in Higher Education, 31, 199-218.

Shute, V. J. (2008). Focus on formative feedback. Review of Educational Research, 153-189.

Winstone, N. E., \& Carless, D. (2020). Designing effective feedback processes in higher education: a learning-focused approach. Routledge. ProQuest Ebook Central.

Winstone, N., Nash, R. A., Rowntree, J., \& Parker, M. (2017). 'It'd be useful, but I wouldn't use it': barriers to university students' feedback seeking and recipience. Studies in Higher Education, 2026-2041.

doi:10.1080/03075079.2015.1130032

Wood, J. (2021). A dialogic technology-mediated model of feedback uptake and literacy. Assessment \& Evaluation in Higher Education, 1-14. doi:10.1080/02602938.2020.1852174 
Xu, Y., \& Carless, D. (2017). 'Only true friends could be cruelly honest': cognitive scaffolding and social-affective support in teacher feedback literacy. Assessment \& Evaluation in Higher Education, 1082-1094. Retrieved from https://www.tandfonline.com/doi/full/10.1080/02602938.2016.1226759

${ }^{1}$ Kerr, W. \& McLaughlin, P. (2008). 'The benefit of screen recorded summaries in feedback for work submitted electronically', 12th Computer Assisted Assessment Conference, Leicestershire, England, viewed 2 February 2019, https://www.reading.ac.uk/web/files/Engagein

Feedback/The_benefit_of_screen_recorded_summaries_in_feedback_for_work_submitted_electronically.pdf

${ }^{2}$ Mathieson, K. (2012). Exploring Student Perceptions of Audiovisual Feedback via Screencasting in Online Courses, American Journal of Distance Education, 26:3, 143-156, DOI: 10.1080/08923647.2012.6891662 Ice, P., Curtis, R., Phillips, P., \& Wells, J. (2007). Using asynchronous audio feedback to enhance teaching presence and students' sense of community. Journal of Asynchronous Learning Networks, 3-25.

${ }^{3}$ Cavaleri, M., Kawaguchi, S., Di Biase, B., \& Power, C. (2019). How recorded audiovisual feedback can improve academic language support, Journal of University Teaching \& Learning Practice, 16(4).

${ }^{4}$ Weaver, M. (2006). Do Students Value Feedback? Student Perceptions of Tutors' Written Responses. Assessment \& Evaluation in Higher Education. 31. 379-394. 10.1080/02602930500353061.

${ }^{5}$ Cavaleri, M., Kawaguchi, S., Di Biase, B., \& Power, C. (2019). How recorded audiovisual feedback can improve academic language support, Journal of University Teaching \& Learning Practice, 16(4).

\section{References}

1. a, b, c, d, e, f, g, h (2020). Re-imagining University Assessment in a Digital World. doi:10.1007/978-3-030-41956-1.

2. `John Hattie, Helen Timperley. (2007). The Power of Feedback. Review of Educational Research, vol. 77 (1), $81-112$. doi:10.3102/003465430298487.

3. ^Philip Ice, Reagan Curtis, Perry Phillips, John Wells. (2019). USING ASYNCHRONOUS AUDIO FEEDBACK TO ENHANCE TEACHING PRESENCE AND STUDENTS' SENSE OF COMMUNITY. OLJ, vol. 11 (2). doi:10.24059/olj.v11i2.1724.

4. `Jon Dron, Catharine Seidel, Gabrielle Litten. (2004). Transactional distance in a blended learning environment. Research in Learning Technology, vol. 12 (2). doi:10.3402/rlt.v12i2.11249. 